\title{
Herpes zoster and postherpetic neuralgia: Past, present and future
}

\author{
Gary J Bennett PhD ${ }^{1}$, C Peter N Watson MD FRCPC ${ }^{2}$
}

GJ Bennett, CPN Watson. Herpes zoster and postherpetic neuralgia: Past, present and future. Pain Res Manage 2009;14(4):275-282.

OBJECTIVES: The history behind the current understanding of the varicella-zoster virus and its relationship to the pain conditions caused by shingles and postherpetic neuralgia are reviewed. The framework for the current conceptualization is Hope-Simpson's latency hypothesis. Data from recent work in virology, neuroanatomy and epidemiology are reviewed, as is work using varicella-zoster virus-infected animals. The recent data largely confirm Hope-Simpson's hypothesis and extend it significantly.

Key Words: Herpes zoster; Neuropathic pain; Postherpetic neuralgia; Varicella

T he varicella-zoster virus (VZV) causes two diseases chickenpox and shingles. The hyphen in the virus' name summarizes more than a century of confusion and debate stemming from an obvious fact - the two diseases have very different presentations. The typical case of chickenpox (varicella) is a child who presents with a bilaterally symmetrical vesicular rash that covers most of the body; the child complains of itch and recovery is usually uneventful. The typical case of shingles (herpes zoster [HZ]) is an elderly adult who presents with a vesicular rash that is limited to a discrete area on one side of the trunk or face; the patient complains of pain, and recovery is sometimes associated with a chronic and intractable pain syndrome - postherpetic neuralgia (PHN). How can such different presentations be due to the same pathogen?

In the present article, we review the history of the search for the answer to this question, and also recent progress on the question of the mechanisms that underlie the pain associated with $\mathrm{HZ}$ infection and PHN. We do not discuss current strategies for the prevention and treatment of $\mathrm{HZ}$ and $\mathrm{PHN}$; recent reviews cover these topics (1-4). It is now clear that various environmental and psychosocial factors have important impacts on PHN. We refer the reader elsewhere for reviews of these factors $(5,6)$.

\section{THE PAST}

Shingles has been recognized as a distinct disease since at least the Middle Ages, and the existence of PHN as a consequence of shingles has been known since the early 19th century (7). In 1900, Head and Campbell (8) published a still-famous paper in the journal Brain that established the concept of the dermatome based on the correlation between the area of skin affected by the $\mathrm{HZ}$ rash and the consequent scarring and degeneration in the trigeminal and dorsal root ganglia found at autopsy. Head was a giant of turn-of-the-century neurology. He endorsed the then-popular opinion that $\mathrm{HZ}$ was an infectious disease

\section{Le zona et l'algie post-zostérienne : Le passé, le présent et l'avenir}

OBJECTIFS : On passe en revue l'histoire qui a mené à la compréhension actuelle du virus varicelle-zona et de son lien avec les douleurs causées par l'algie post-zostérienne. L'hypothèse de latence de Hope-Simpson forme le cadre actuel de conceptualisation. On examine les données tirées de récents travaux en virologie, en neuroanatomie et en épidémiologie, de même que de travaux faisant appel à des animaux infectés par le virus varicelle-zona. Les données récentes confirment largement l'hypothèse de Hope-Simpson et la poussent beaucoup plus loin.

that appears in epidemics, similar to chickenpox and measles, and that it was acquired directly from another person with $\mathrm{HZ}$ (9). While popular, this hypothesis did not address a wellknown phenomenon - children in contact with an adult with HZ developed an illness that appeared to be identical to varicella. Varicella resulting from exposure to $\mathrm{HZ}$ was known as Z-varicella to distinguish it from the ordinary childhood disease, which was designated as $\mathrm{O}$-varicella. Confirmation of this link between varicella and HZ came from an experiment (10) that seems shocking today - healthy children were inoculated with fluid from an $\mathrm{HZ}$ vesicle from an adult and shown to develop a condition that appeared to be identical to varicella; also, they could transmit the condition to other children.

By the mid 20th century, some accepted the idea that childhood O-varicella and Z-varicella were the same disease. For example, Abramson (11) reported an outbreak of O-varicella among hospitalized children in which those in contact with the children were protected by inoculation with plasma from adult patients convalescing from HZ. With today's knowledge of the exquisite specificity of the immune system, this would be evidence that $\mathrm{O}$-varicella and $\mathrm{Z}$-varicella were caused by the same pathogen. However, such confidence in immunospecificity was not widespread in that day and a skeptic may have argued the infection that started it all was Z-varicella. As late as the 1950s, opinion was still divided regarding the relationship between O-varicella and Z-varicella. For example, Barnett (12) proposed that the link between $\mathrm{HZ}$ and varicella was indirect $-\mathrm{HZ}$ occurred when a person with fading immunity to varicella encountered the agent that caused $\mathrm{HZ}$. Opposition to the proposal that $\mathrm{O}$-varicella and $\mathrm{Z}$-varicella were identical was not mere stubbornness. After all, the causative agent had not been identified conclusively and accepting the identity hypothesis gave rise to an unsolved problem - if O-varicella and $\mathrm{Z}$-varicella in children were the same disease, then what

${ }^{1}$ Department of Anesthesia, Faculty of Dentistry, and The Alan Edwards Centre for Research on Pain, McGill University, Montreal, Quebec;

${ }^{2}$ Department of Medicine, University of Toronto, Toronto, Ontario

Correspondence and reprints: Dr Gary J Bennett, McGill University, 3655 Promenade Sir William Osler, McIntyre Building, Room 1202,

Montreal, Quebec H3G 1Y6. Telephone 514-398-3432, fax 514-398-8241, e-mail gary.bennett@mcgill.ca 
was $\mathrm{HZ}$ in an adult? The answer came from the observations of a remarkable general practitioner and self-taught epidemiologist named Edgar Hope-Simpson, who practiced in the ancient Cotswolds town of Cirencester (United Kingdom).

\section{Hope-Simpson and the latency hypothesis}

At the time of Hope-Simpson's work (9), general practitioners in the United Kingdom had a unique opportunity for pursuing observational research. They were serving a relatively stable population of several thousand people of all ages, thus allowing the physician to follow his cases for many years, and patients were easily characterized by their data on the National Health Service List. The general practitioner was probably consulted for every case of $\mathrm{HZ}$ in his practice. This opportunity was fleeting. Within just a few decades, general practitioners began to amalgamate into large group practices in which individual doctors lacked a personal list, and long-term follow-up became difficult as the postwar population became increasingly peripatetic.

Hope-Simpson formed an epidemiology research unit in Cirencester that focused on the bionomic features of infectious diseases - for example, the time from infection to illness and the disease's serial interval (ie, the interval between illnesses in the donor and recipient). He found that measles, mumps and O-varicella each had their own highly individual and consistent pattern of bionomic characteristics. Although he had worked out the bionomics of O-varicella, he believed that comparable efforts on Z-varicella would be inconclusive in Cirencester because of potential cross-infections from surrounding large towns. His attention was thus drawn to an article in the British Medical Journal (13) describing an attack of $\mathrm{HZ}$ in a teacher that had initiated an outbreak of varicella among the students in her school on the remote Shetland island of Yell (United Kingdom). Hope-Simpson corresponded with the teacher and learned that a similar incident was in progress - a crofter in the nearby hamlet of Herra had developed HZ, and his five school-aged children had developed varicella and infected their schoolmates.

Hope-Simpson and his team went to the island and collected the case histories. Their analysis of the data revealed that the bionomic features of $\mathrm{Z}$-varicella were identical to those of O-varicella in both Yell and Cirencester. His data showed conclusively that $\mathrm{HZ}$ did not come in epidemics and was not more abundant in years with varicella epidemics. Furthermore, he found that persons with a history of $\mathrm{O}$-varicella who were at household risk of infection with Z-varicella were completely cross-protected, whereas, had there been no cross-protection, $60 \%$ would have developed Z-varicella. Hope-Simpson (14) was thus convinced that varicella and $\mathrm{HZ}$ were caused by the same agent. His conclusion was supported by the work of Thomas Weller and his colleagues in Boston (USA) (15-17) who used what were then the most modern methods of virological investigation and had shown that the varicella virus appeared to be identical to the virus isolated from HZ lesions. Still, if the two diseases were due to the same pathogen, why did chickenpox and shingles look so different?

Hope-Simpson solved the puzzle with the latency hypothesis, a revolutionary proposal that $\mathrm{HZ}$ is due to the reactivation of a latent varicella infection in a sensory ganglion (18). He further hypothesized that viral latency is maintained by immunosurveillance, which is boosted by periodic subclinical reactivations and exposure to exogenous virus, and that reactivation (ie, HZ) appears when immunosurveillance falls below a critical threshold. His hypothesis explained the puzzling dermatomal predilection of $\mathrm{HZ}$, which is most often seen in the thoracic and trigeminal dermatomes, as a consequence of those ganglia being seeded with a larger quantity of viral particles during the varicella attack, when the varicella rash is usually heaviest on the trunk and face. His summary diagram of the latency hypothesis is republished in contemporary textbooks (Figure 1).

\section{THE PRESENT}

\section{Immunosurveillance}

Nearly half a century later, our ideas about varicella and $\mathrm{HZ}$ are little changed from Hope-Simpson's proposal. His idea that latency is boosted by an infected person's periodic exposure to exogenous virus has been proven repeatedly, with perhaps the nicest example being a study showing that $\mathrm{HZ}$ is approximately one-half as common in pediatricians as in psychiatrists (19). However, Hope-Simpson's belief that the critical parameter of immunosurveillance was the plasma level of B cell-secreted antibodies is now known to be incorrect. The critical parameter is T cell-mediated immunity $(20,21)$.

Hope-Simpson's proposal that exposure to exogenous virus boosts an adult's immunocompetency and keeps HZ at bay suggests that it may be possible to vaccinate adults against $\mathrm{HZ}$. This prediction has been confirmed (22). More than 38,000 subjects 60 years of age or older were treated with a vaccine prepared from the live, attenuated Oka/Merck VZV strain (a more potent vaccine than that used in children). After a median period of postvaccination observation of approximately three years, vaccination reduced the incidence of $\mathrm{HZ}$ by $51.3 \%$ and the incidence of PHN by $66.5 \%$. Vaccinated patients who nevertheless did develop HZ experienced pain that was significantly less intense and of shorter duration than that experienced by nonvaccinated cases. Moreover, vaccinated patients who developed PHN had pain syndromes that were less severe than those of nonvaccinated patients. Thus, the vaccine not only prevented disease but also attenuated it.

\section{Viral evolution}

Hope-Simpson (18) believed that the VZV virus evolved the latency strategy to perpetuate itself in the small and isolated bands that characterized the population structure of primitive humans. In effect, the virus hid in adults until a new generation of hosts was born. The idea that VZV is an ancient affliction has been confirmed by modern molecular biology. Mapping mutations in the human mitochondrial genome across diverse populations allows for a reconstruction of human migrations and has led to the 'out of Africa' hypothesis for the origins of modern man. The same sort of analysis has been performed on the genomes of isolates of VZV strains from around the world. The geographical pattern of mutations in the viral genome matches that of the human genome, thus supporting the idea that the virus has travelled with man for hundreds of thousands of years. Indeed, comparing the VZV genome with the genomes of other viruses in the alpha-herpesvirus family indicates that VZV originated 60 to 70 million years ago in African primates $(23,24)$. It is thus possible that the virus infected our Australopithecus ancestors. 


\section{Epidemiology of $\mathrm{HZ}$ and PHN in Canada}

Our understanding of the epidemiology of $\mathrm{HZ}$ and PHN is far better than in Hope-Simpson's day. For example, the incidence of HZ in Canada has been estimated from studying the billing records of Manitoba physicians during the period from 1979 to 1997 (25,26). The Canadian estimates are very close to those from the United States and the United Kingdom, and are very likely to be close to those of all developed countries in the temperate latitudes. The epidemiology of $\mathrm{HZ}$ and $\mathrm{PHN}$ in underdeveloped countries will likely differ because of several factors that affect the spread of the virus (eg, the number of children attending primary school).

In the Canadian population (approximately 30 million), 130,000 people will develop HZ each year. Men and women will be affected approximately equally. More than 46,000 of these people will be 65 years of age or older. Over 5000 cases will occur in people who are at particular risk because of an immunosuppressive condition. Over 4000 individuals will be admitted to hospital and approximately 30 will die from complications. In each yearly cohort of $130,000 \mathrm{HZ}$ patients, approximately 17,000 will develop PHN and join the population of PHN sufferers from previous years. The majority of the new PHN patients will be older than 60 years of age; men and women will be affected equally (27).

The estimated Canadian health care cost for HZ and PHN is more than $\$ 67$ million. This estimate does not capture the full impact of PHN pain, which is rarely eliminated by available therapies and often completely refractory to treatment. Nearly one-half of PHN patients will report daily pain of moderate intensity ( 3 to 7 on a 0 to 10 scale, in which 10 is the 'worst pain imaginable'). Approximately $20 \%$ of $\mathrm{PHN}$ patients will report severe daily pain (greater than 7 ). As is expected from such a severe burden, the patients experience significant decreases in their daily activities, significantly impaired sleep and clinically significant depression (27).

\section{Zoster-associated pain}

A child with varicella complains of itch, but an adult with $\mathrm{HZ}$ complains of pain, and in the case of PHN, the pain remains after the virus re-enters dormancy. Research has begun to shed light on the source of the pain.

It is possible that there are at least some pain mechanisms that contribute to both the pain of shingles and the pain of PHN. The concept of zoster-associated pain reflects this possibility. It is difficult to make a precise determination of when pain ceases to be due to the attack of shingles and begins to be due to PHN. For most shingles patients, the pain resolves in a few weeks, at approximately the time when the rash begins to heal, but for the PHN patient, the pain persists long after the disappearance of signs of active viral replication. There is often no pain-free interval between the pain of shingles and the PHN pain. In clinical trials, PHN has usually been defined somewhat arbitrarily as pain lasting for more than three or four months after the appearance of the rash.

\section{Pain mechanisms in acute $\mathrm{HZ}$}

In shingles, viral particles originating in the trigeminal or dorsal root ganglion (DRG) neuron travel antidromically (ie, down the cell's axon) to the sensory terminals in the skin. The rash begins when the virus escapes the nerve terminals and invades the skin. The resulting rash is accompanied by an

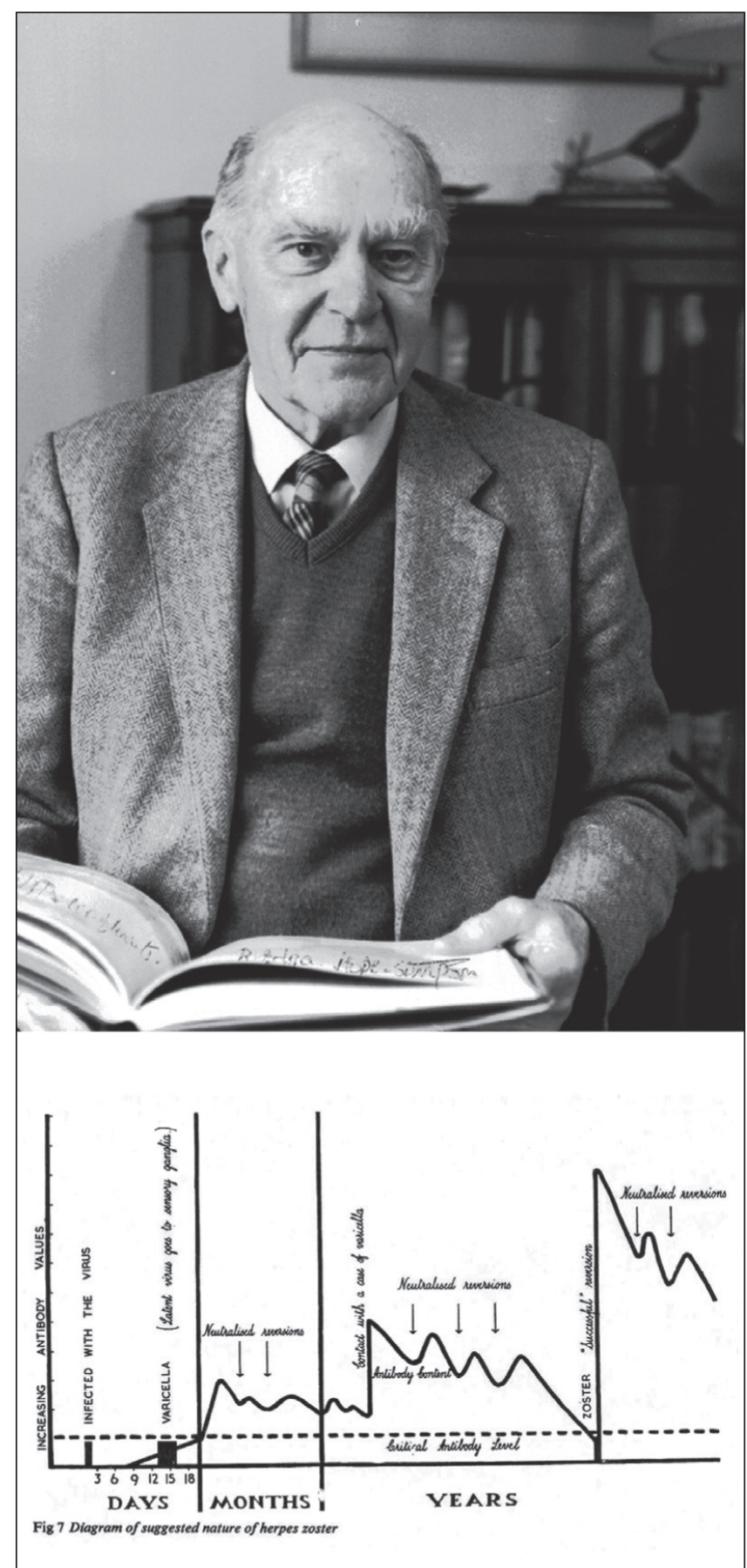

Figure 1) Top: R Edgar Hope-Simpson at the age of 90. HopeSimpson's epidemiological work was centred in Cirencester (United Kingdom), but his insights on the nature of varicella-zoster infection were the result of studying the isolated population of the Shetland island of Yell (United Kingdom). Bottom: The original schematic diagram of Hope-Simpson's latency hypothesis (16)

obvious inflammatory response and it is possible that this inflammation sensitizes pain-specific sensory fibres (nociceptors). Sensitized nociceptors have a lowered activation threshold, such that they are excited by normally innocuous stimuli such as gentle touching (allodynia), and an increased response to stimuli that are more intense than the normal threshold, such that normally painful stimulation causes greater than 


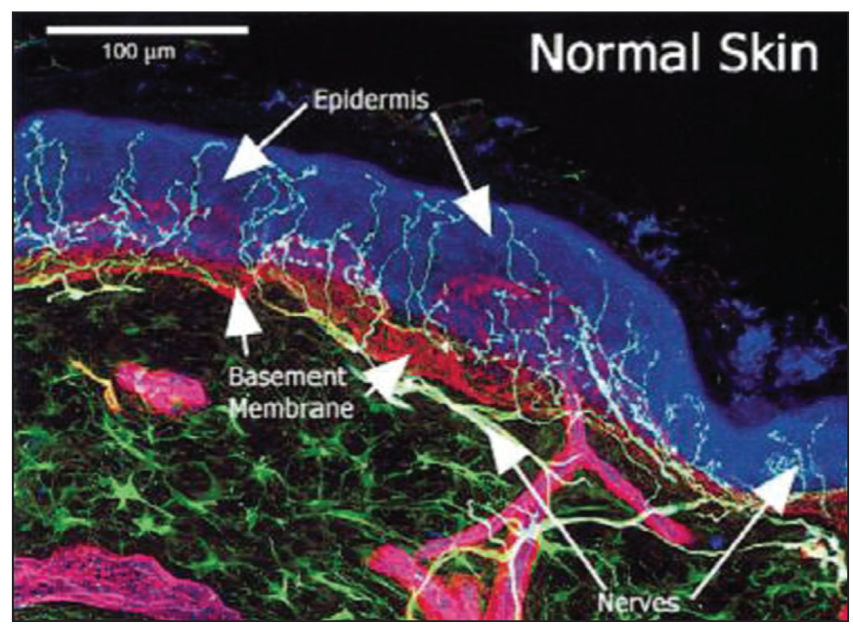

Figure 2) Section of a punch biopsy from normal human skin stained with the pan-neuronal marker protein gene product 9.5. Nerve fibre bundles (green and yellow) course within the superficial dermis beneath the basement membrane (red) that separates the dermis from the epidermis (blue). Individual sensory axons (white) leave the dermal bundles, ascend, penetrate the basement membrane and ramify within the epidermis. Counting these intraepidermal nerve fibres affords a precise way to quantify the degree of sensory denervation following an attack of shingles. Reproduced from reference 59 with permission

normal pain (hyperalgesia). Sensitized nociceptors also have an abnormal spontaneous discharge that is likely to cause spontaneous pain sensations (28).

However, the pain of shingles has causes that are distinct from those arising from the skin, as shown clearly by the common presence of pain occurring days or even months before the rash appears (prodromal pain) and the rare cases in which there is pain but the rash never appears (zoster sine herpete). Replicating virus in heavily infected neurons is likely to cause direct neurolytic lesions to the cell bodies or their axons, and indirect injury via the endoneurial inflammatory response and hemorrhage that occur as virus particles escape from damaged neurons and axons. Thus, potential mechanisms for neuropathic pain exist at the same time - and may even come before - the mechanisms that underlie cutaneous inflammatory pain.

Breaches in the axonal membrane cause short-circuit-like discharges of nerve impulses ('injury discharge'). If membrane defects are small and repaired, the cell can generate repeated episodes of injury discharge. Injury discharge from nociceptors and the discharge of sensitized nociceptors will release the neurotransmitter glutamate onto spinal cord dorsal horn neurons that express the $\mathrm{N}$-methyl-D-aspartate subtype of glutaminergic receptor. $\mathrm{N}$-methyl-D-aspartate receptor activation engages a process called central sensitization in the spinal cord neurons that send pain information to the brain. Central sensitization is believed to result in a significant amplification of the spinal cord neurons' responses to sensory input $(29,30)$.

\section{Pain mechanism in PHN}

There is no strong evidence to link chronic PHN pain with ongoing viral replication in the trigeminal ganglion or DRG, or in the central nervous system (CNS). The cessation of the period of active viral replication in shingles is generally believed to approximately coincide with the healing of the cutaneous rash. However, controversy exists as to when viral replication ceases in the peripheral ganglia and CNS. Autopsies of chronic PHN patients have detected leukocytes in areas of CNS degeneration (31), but it is not clear whether these cells are responding to the presence of active virus or to the products of degeneration. Circulating immune cells harbour VZV before, during and shortly after an attack of shingles. If there is active viral replication during chronic PHN, then one would expect to find infected immune cells. However, even the highly sensitive polymerase chain reaction method fails to find any evidence of viral replication in chronic PHN patients $(32,33)$.

The use of skin punch biopsies labelled with an antibody that recognizes the pan-neuronal marker protein gene product 9.5 allows for the quantification of the sensory fibres that innervate the skin (Figure 2). Comparison of skin biopsies among $\mathrm{HZ}$ patients who did or did not develop PHN reveals a loss of sensory fibres that is far worse in the PHN patients (34). A study of biopsies from 38 postshingles patients showed PHN to be present almost exclusively in those with fewer than 650 remaining sensory fibres per square millimetre of skin surface (35). This suggests that there may be a nonlinear, step-function relationship between the severity of sensory fibre degeneration and the appearance of PHN. Surprisingly, studies of skin biopsies from the contralateral 'mirror-image' sites reveal that PHN patients have focal losses of approximately one-half of the epidermal nerve fibres in these pain-free regions (34). Even more surprisingly, the severity of PHN pain correlates significantly with the severity of this contralateral fibre loss. Other authors subsequently appreciated that their data also indicated bilateral effects of unilateral shingles $(36,37)$. It may be that the contralateral loss of peripheral fibres is secondary to a subclinical extension of viral inflammation into the spinal cord (38). However, significant contralateral denervation (50\%) has also been shown in rats with a surgical lesion to the nerve on the other side (39). Indeed, there is evidence for many contralateral abnormalities after unilateral nerve injury in animals (40). However, the presence of extensive contralateral degeneration where there is no pain suggests that the ipsilateral loss of nerve fibres may not sufficiently explain the cause of pain.

\section{CNS pathology}

For many years, the standard concept of the anatomical damage caused by an attack of shingles was based on the postmortem studies that Head and Campbell reported in 1900 (8). They showed that, at the onset of HZ, a violent hemorrhagic inflammation occurs in the ganglion and adjacent nerve (Figure 3) and, over time, results in extensive fibrosis and loss of nerve cells and fibres in the ganglion, root and peripheral nerve (Figure 3). It is not known whether any of the patients autopsied by Head and Campbell had PHN. More than eight decades passed before it was shown that DRG scarring and nerve cell loss are also present in PHN patients $(31,37,41)$. These studies also found that PHN is associated with severe atrophy of the dorsal horn (Figure 3 ) of the spinal cord at the level of the damaged DRG, and at spinal levels above and below. These data show that PHN is associated with irreparable damage to both the peripheral nervous system and the CNS, and suggest that the CNS damage may be of particular importance to the genesis of PHN pain. 


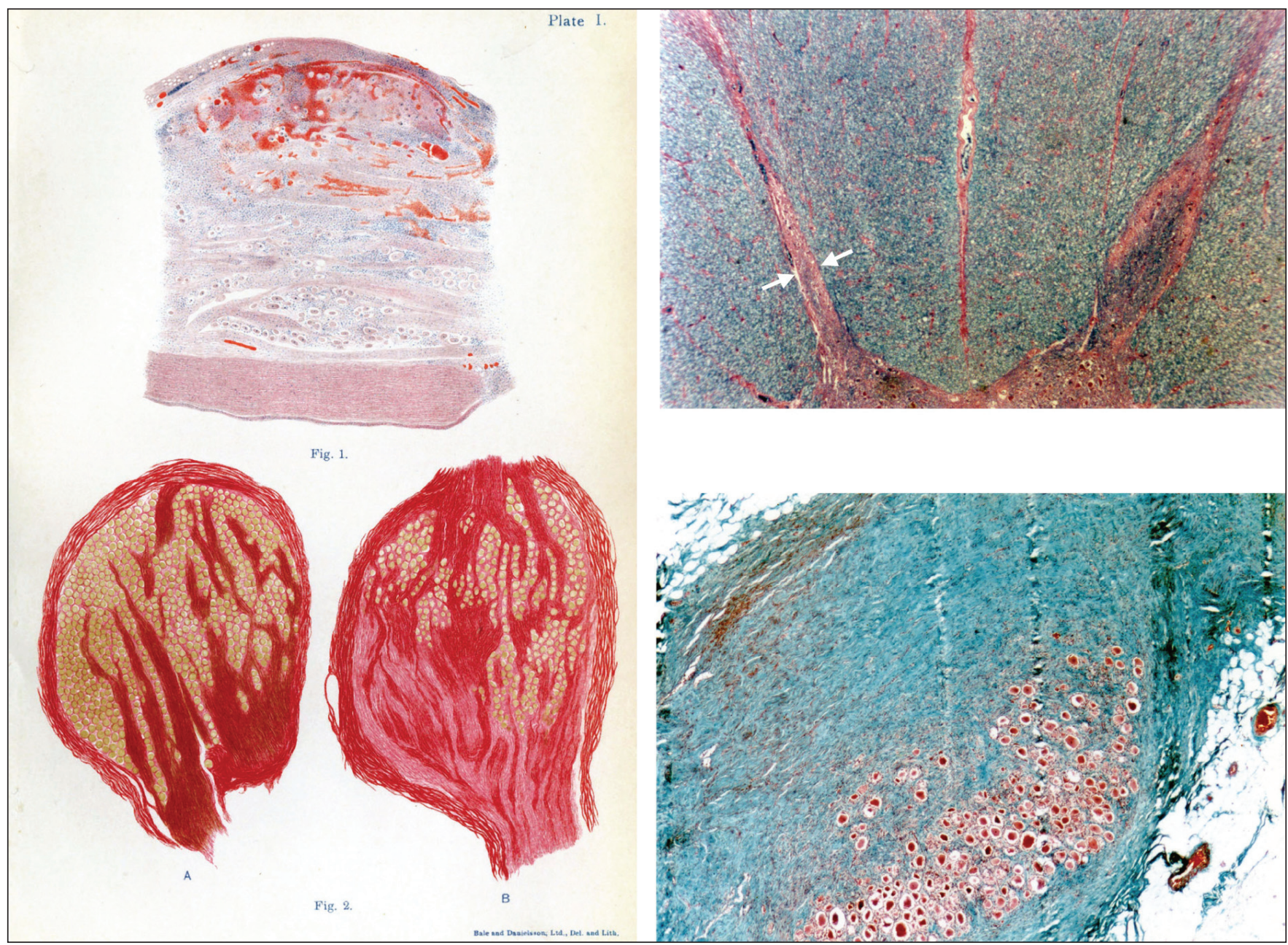

Figure 3) Left panel: Plate 1 from Head and Campbell's 1900 paper (8) showing the inflammatory and hemorrhagic effects of acute shingles. These drawings were made with a camera lucida drawing tube attached to the microscope and were subsequently hand-coloured. They are among the finest medical illustrations of the pre-Photoshop era. Top: Longitudinal section through the seventh thoracic dorsal root ganglia (DRG) from the affected side of a patient who died eight days after the onset of shingles. Extensive hemorrhage is seen in the dorsal part of the DRG that contains the cell bodies of primary afferent somatosensory neurons. Bottom: DRG sections from the seventh thoracic ganglia of a patient who died five months after the onset of shingles. The normal side is shown on the left and the affected side with extensive scarring is shown on the right. Shingles is rarely a fatal disease, but AW Campbell was a pathologist for the Rainhill County Asylum, which cared for the elderly poor and afforded ample material for study. Right panel: Section of the thoracic spinal cord (top) and eighth thoracic DRG (bottom) of a patient who died after a five-year history of severe postherpetic neuralgia. The spinal cord posterior horn is atrophied (arrows) on the affected side. Similar atrophy ran for seven spinal segments, although only one of the patient's DRGs showed the characteristic scarring caused by shingles. Before this finding, extensive central nervous system pathology was not known to be present in postherpetic neuralgia. The lower right portion of the DRG contains normal neuronal cell bodies (white and red), but cells are missing throughout the fibrotic remainder. Reproduced from reference 41 with permission

\section{$\mathrm{HZ}$ and $\mathrm{PHN}$ in laboratory animals}

VZV is exquisitely tailored to the human host and it is thus very difficult to cause an active VZV infection in laboratory animals. Limited success can be achieved when VZV is grown for a long time in cultures of guinea pig cells. This yields a 'conditioned' virus that can successfully infect guinea pigs. The use of a mutant strain of guinea pig that does not grow fur allows the rash to be monitored (42). The problem with the guinea pig model is, of course, that one does not know what changes have been induced in the human virus by the conditioning process.

It was thus a landmark discovery when Sadzot-Delvaux et al $(43,44)$ found that a latent infection in the rat's DRG could be established by a simple subcutaneous injection of cultured cells that bore a human VZV infection. The latent infection occurs without an active infection (ie, the virus does not replicate in the animal) and no cutaneous rash is formed. No one has succeeded in reactivating such a latent infection in the live animal, which would be a true model of shingles. However, it is possible to induce viral reactivation in cultured DRG neurons removed from a rat with this type of latent infection, showing that the infection is truly latent, rather than abortive. The latent infection lasts for at least nine months, which is a long time relative to a rat's life span of approximately 2.5 years. The latent virus is found almost exclusively in the lumbar DRG corresponding to the dermatome that received the injection, 
showing that the virus enters the neuron via retrograde transport along the neuron's axon - the same path used to establish a clinical latent infection.

Remarkably, rats with this latent infection develop clear signs of neuropathic pain on the hind paw that received the inoculation (45-48). There are well-established methods for determining pain sensitivity in laboratory rodents (49). For example, successively stiffer von Frey 'hairs' (actually, nylon monofilaments of different diameters that exert defined levels of force when pressed against a surface to the point at which they bend) can be applied to the sole of the hind paw. The threshold force that evokes the protective withdrawal reflex defines the animal's pain threshold. Heat hypersensitivity can be inferred from the latency of the withdrawal reflex evoked by shining a hot light through a glass pane that the animal stands on. Normal rats respond with a latency that corresponds to a skin temperature of approximately $45^{\circ} \mathrm{C}$; this is also the normal human heat-pain threshold (it is the temperature at which protein degradation, and hence tissue damage, begins). Following the induction of the latent VZV infection, stimulation of the ipsilateral hind paw evokes a withdrawal reflex to weak von Frey hairs that rarely, if ever, evoke a withdrawal reflex in the normal case. As well, heat evokes a withdrawal reflex at latencies corresponding to temperatures that do not ordinarily evoke pain. Such hypersensitivity to touch (allodynia) and heat is often present in PHN patients. Some, but not all, PHN patients also have hypersensitivity to cold, such that even gentle cooling produces pain (50). This abnormal cold-evoked pain does not appear to be present in the rats. PHN patients also report spontaneous pain, ie, pain that does not appear to be related to any stimulation. There are no validated methods to measure spontaneous pain in animals and it is thus unknown whether the latently infected rats have spontaneous pain.

The pain hypersensitivity begins as early as three days after the inoculation and lasts for 60 to 100 days. Some studies $(46,48)$ have noted an additional, relatively mild and brief period of pain hypersensitivity on the hind paw contralateral to the inoculation. The reason for this contralateral pain is unknown. Clinically, bilateral PHN is very rare. However, as noted above, PHN is associated with symptomatically silent lesions to sensory neurons that innervate skin contralateral to the rash (34).

Control inoculation with uninfected cells has no effect on pain sensitivity. Moreover, control injections of cells infected with human herpes simplex virus type 1 produce only a few days of modest pain hypersensitivity (46). The herpes simplex virus type 1 pain hypersensitivity is prevented by valacyclovir treatment, while the pain hypersensitivity produced by VZV injection is not $(46,48)$. One can thus conclude that the longlasting pain hypersensitivity seen with the latent VZV infection is not secondary to an inflammatory response to the presence of virus per se, or to a reaction to the cells that the virus is grown in, and that it is not associated with viral replication.

The incidence of rats developing the pain syndrome and the severity and duration of the syndrome are roughly correlated with the amount of virus inoculated $(47,48)$. This may be related to the clinical observation that PHN is more likely when the acute attack of shingles is severe or untreated (51). In the rat, comparable pain syndromes have been found with VZV from different viral strains, including clinical isolates from patients who did, and who did not, develop PHN (48). This suggests that the development of the pain is likely to be a function of the host's response to the virus, rather than a mechanism intrinsic to the virus itself.

The pain syndrome seen in rats with a latent VZV infection seems to have a pharmacological response profile that is similar to that of PHN pain $(47,48,52)$. The rats' pain is relieved by antidepressants, sodium channel blockers (mexiletine), and antiepileptics (gabapentin and lamotrigine). There is evidence that WIN 55,212-2 (a cannabinoid receptor agonist) is also effective in these animals. Whether the pain syndrome in rats responds to opioid and anti-inflammatory analgesics (ibuprofen and diclofenac) is controversial.

\section{THE FUTURE}

\section{Epidemiology}

Increasing childhood vaccination against varicella, increasing awareness of the need for instituting aggressive antiviral therapy within the first three days of the attack (53), and the introduction of the adult vaccine will surely decrease the incidence of shingles and PHN, but to an extent that is not yet clear and on a timeline that is very difficult to predict. On the other hand, the number of patients with particular susceptibility to $\mathrm{HZ}$ will increase steadily as the percentage of the elderly in the population and the number of immunocompromised patients increase (eg, transplant recipients, HIV patients, cancer patients receiving radiation and chemotherapy, etc).

Mathematical modelling indicates that increasing rates of childhood varicella vaccination may have the paradoxical effect of increasing the rate of $\mathrm{HZ}$ infection because adults from the prevaccine era will be exposed to less exogenous virus and thus will not receive the periodic boosting of immunosurveillance that keeps the disease in check $(54,55)$. This could be a very significant effect, with an anticipated increase in the incidence of $\mathrm{HZ}$ of up to $40 \%$ to $50 \%$ during the next 20 to 50 years. It is still too early in the vaccine era to be certain that this increase will occur. Childhood varicella vaccination was approved by the United States Food and Drug Administration in 1995, and by Health Canada in 2006; the adult HZ vaccine entered the American market in 2006 and was approved for use in Canada in September 2008.

\section{Pain mechanisms}

The historical picture of PHN as being associated with a unilateral, one-level, sensory ganglionopathy with axonal degeneration extending peripherally is incomplete. It is now clear that the pathological features associated with PHN include particularly severe peripheral axonal loss, degeneration of the sensory neuron's centrally directed axon, multisegmental dorsal horn atrophy and the presence of clinically nonsymptomatic contralateral changes in the innervation of the skin. How this pathology produces PHN pain is not yet understood. There is also the possibility of CNS abnormalities not visible by light microscopy, or abnormalities at higher levels of the neuroaxis that have not yet been characterized. Excessive discharge in injured peripheral axons may cause secondary damage to neurons in the spinal cord dorsal horn $(56,57)$. For research purposes, it is now clear that the contralateral mirror-image site 
can no longer be considered a normal site suitable for gathering control data.

In humans, PHN pain occurs after a reactivated infection that causes great damage to sensory neuron cell bodies in the ganglion and to their axons. It has always been assumed that the pain is somehow associated with this neuronal damage. However, in the latently infected rat, it seems that there is a PHN-like pain syndrome that is not associated with any neuronal damage. The latently infected DRG shows no sign of an inflammatory reaction, hemorrhage or neuronal degeneration $(45,47)$. This suggests a novel hypothesis - the pain seen in rats with a latent VZV infection may be due to changes in neuronal function caused by the mere presence of the virus, and that this may also be true of PHN pain.

It has generally been believed that the virus is completely inactive during the latent period. It is now known that, in a latent VZV infection, the virus is actively expressing six genes (58). The function of these latency-associated gene products is not known, but their presence suggests that latency is a process actively maintained by the virus itself. It is possible that one or more of these gene products may alter neuronal function.
Neuronal injury occurs in every patient with shingles; however, only some experience PHN, and nerve fibre loss is documented contralaterally where there is no pain. It is thus clear that neuronal injury is not a sufficient explanation for the development of PHN pain. The rat data suggest that neuronal damage may be neither sufficient nor necessary for the development of PHN pain.

VZV has been with us for many thousands of years - it probably has more surprises in store for us.

STATEMENT OF INTERESTS: Preparation of this article was supported in part by Merck Frosst Canada, Ltd. Within the past year, GJB accepted consulting fees and/or speaker's honoraria from Allon Therapeutics (Canada), Endo Pharmaceuticals (USA), Johnson \& Johnson (USA), KAI Pharmaceuticals (USA), WEX Pharmaceuticals (Canada) and Xanodyne Pharmaceuticals (USA), and has a research contract with Trophos SA (France). CPNW accepted speaker's honoraria from Merck (USA), Pfizer (USA) and Purdue (USA), and has a research contract with Purdue. Neither author is a major shareholder or has any significant financial relationship with any relevant commercial interest.

\section{REFERENCES}

1. Gilron I, Watson CPN, Cahill CM, Moulin DE. Neuropathic pain: A practical guide for the clinician. CMAJ 2006;175:265-75.

2. Harpaz R, Ortega-Sanchez IR, Seward JF. Prevention of herpes zoster: Recommendations of the Advisory Committee on Immunization Practices (ACIP). MMWR Recomm Rep 2008;57(RR-5):1-30.

3. Opstelten W, Eekhof J, Neven AK, Verheij T. Treatment of herpes zoster. Can Fam Physician 2008;54:373-7.

4. Wu CL, Raja SN. An update on the treatment of postherpetic neuralgia. J Pain 2008;9(Suppl 1):S19-30.

5. Jung BF, Johnson RW, Griffin DR, Dworkin RH. Risk factors for postherpetic neuralgia in patients with herpes zoster. Neurology 2004;62:1545-51.

6. Katz J, McDermott MP, Cooper EM, Walther RR, Sweeney EW, Dworkin RH. Psychosocial risk factors for postherpetic neuralgia: A prospective study of patients with herpes zoster. J Pain 2005;6:782-90.

7. Abraham N, Murray J. The belt of roses from hell: Historical aspects of herpes zoster and postherpetic neuralgia. In: Watson CPN, Gershon AA, eds. Herpes Zoster and Postherpetic Neuralgia. Amsterdam: Elsevier, 2001:20-3.

8. Head H, Campbell AW. The pathology of herpes zoster and its bearing on sensory localization. Brain 1900;23:353-523.

9. Hope-Simpson RE. Some early investigations into the nature of herpes zoster and postherpetic neuralgia. In: Watson CPN, Gershon AA, eds. Herpes Zoster and Postherpetic Neuralgia, 2nd edn. Amsterdam: Elsevier, 2001:1-12.

10. Kundratitz K, Ueber die aetiologie des Zoster und Uber seine Beziehungen zu Varizellen. Wien Klin Wochenschr 1925;38:502-3.

11. Abramson AW. Varicella and herpes zoster: An experiment. Br Med J 1944;1:812-3.

12. Barnett $\mathrm{CH}$. The relationship between herpes zoster and varicella. Med Pr 1950;223:126-8.

13. Petersen PH, Black SAB. Varicella herpetiformis. Br Med J 1946;1:762.

14. Hope-Simpson RE. Studies on shingles. Is the virus ordinary chickenpox virus? Lancet 1954;25:1299-302.

15. Weller TH, Stoddard MB. Intranuclear inclusion bodies in cultures in human tissues inoculated with varicella vesicle fluid. J Immunol 1952;68:311-9.

16. Weller TH, Coons AH. Fluorescent antibody study with agents of varicella and herpes zoster propagated in vitro. Proc Soc Exp Biol 1954;86:789-94.

17. Weller TH, Witton HM, Bell EJ. The etiologic agents of varicella and herpes zoster. Serologic studies with the viruses as propagated in vitro. J Exp Med 1958;108:843-68.

18. Hope-Simpson RE. The nature of herpes zoster: A long-term study and a new hypothesis. Proc R Soc Med 1964;58:9-20.

19. Solomon BA, Kaporis AG, Glass AT, Simon SI, Baldwin HE. Lasting immunity to varicella in doctors study (L.I.V.I.D. study). J Am Acad Dermatol 1998;38:763-5.

20. Miller AE. Selective decline in cellular immune response to varicella-zoster in the elderly. Neurol 1980;30:582-7.

21. Weller TH. Varicella and herpes zoster: Changing concepts of the natural history, control, and importance of a not-so-benign virus. N Engl J Med 1983;309:1434-40.

22. Oxman MN, Levin MJ, Johnson GR, et al. A vaccine to prevent herpes zoster and postherpetic neuralgia in older adults. N Eng J Med 2005;352:2271-84.

23. Wagenaar TR, Chow VT, Buranathai C, Thawatsupha P, Grose C. The out of Africa model of varicella-zoster virus evolution: Single nucleotide polymorphisms and private alleles distinguish Asian clades from European/North American clades. Vaccine 2003;21:1072-81.

24. Wang N, Baldi PF, Gaut BS. Phylogenetic analysis, genome evolution and the rate of gene gain in the Herpesviridae. Mol Phylogenet Evol 2007;43:1066-75.

25. Brisson M, Edmunds WJ, Law B, et al. Epidemiology of varicella zoster virus infection in Canada and the United Kingdom. Epidemiol Infect 2001;127:305-14.

26. Brisson M, Pellisseir JM, Camden S, Quach C, De Wals P. The potential cost-effectiveness of vaccination against herpes zoster and post-herpetic neuralgia. Hum Vaccin 2008;4:238-45.

27. Brisson M, Johnson RW, Levin MJ, et al. Measuring herpes zoster (HZ) and post-herpetic neuralgia (PHN) associated burden of illness, health care utilization, and costs in Canada: A clinical epidemiological study. Can J Infect Dis Med Microbiol 2006;17:381.

28. Bennett GJ. Hypotheses on the pathogenesis of herpes zosterassociated pain. Ann Neurol 1994;35:S38-41.

29. Woolf CJ. Generation of acute pain: Central mechanisms. Br Med Bull 1991;47:523-33.

30. Gracely RH, Lynch S, Bennett GJ. Painful neuropathy: Altered central processing, maintained dynamically by peripheral input. Pain 1992;51:175-94.

31. Watson CPN, Deck JH, Morshead C, Van der Kooy D, Evans RJ. Postherpetic neuralgia: Further postmortem studies of cases with and without pain. Pain 1991;44:105-17.

32. Mainka C, Fuss B, Geiger H, Höfelmayr H, Wolff MH. Characterization of viremia at different stages of varicella-zoster virus infection. J Med Virol 1998;56:91-8. 
33. Schünemann S, Mainka C, Wolff MH. No acute varicella-zoster virus replication in peripheral blood mononuclear cells during postherpetic neuralgia. Acta Virol 1999;43:337-40.

34. Oaklander AL, Romans K, Horasek S, Stocks A, Hauer P, Meyer RA. Unilateral postherpetic neuralgia is associated with bilateral sensory neuron damage. Ann Neurol 1998;44:789-95.

35. Oaklander AL. The density of remaining nerve endings in human skin with and without postherpetic neuralgia after shingles. Pain 2001;92:139-45.

36. Baron R, Saguer M. Axon reflex reactions in affected and homologous contralateral skin after unilateral peripheral injury of thoracic segmental nerves in humans. Neurosci Lett 1994;165:97-100.

37. Watson CPN, Midha R, Devor M, Nag S, Munro C, Dostrovsky JO. Trigeminal postherpetic neuralgia postmortem: Clinically unilateral, pathologically bilateral. In: Devor M, Rowbotham MC, Wiesenfeld-Hallin Z, eds. Proceedings of the 9th World Congress on Pain. Progress in Pain Research and Management. Seattle: IASP Press, 2000:733-9.

38. Haanpaa M, Dastidar P, Weinberg A. CSF and MRI findings in patients with acute herpes zoster. Neurology 1998;51:1045-411.

39. Oaklander AL, Brown JM. Unilateral nerve injury produces bilateral loss of distal innervation. Ann Neurol 2004;55:639-44.

40. Koltzenburg M, Wall PD, McMahon SB. Does the right side know what the left side is doing? Trends Neurosci 1999;22:122-7.

41. Watson CPN, Morshead C, Van Der Kooy D, et al. Postherpetic neuralgia: Postmortem analysis of a case. Pain 1988;34:129-38.

42. Myers MG, Connelly BL. Animal models of varicella. J Infect Dis 1992;166:S48-50.

43. Sadzot-Delvaux C, Merville-Louis MP, Delree P, et al. An in vivo model of varicella-zoster virus latent infection of dorsal root ganglia. J Neurosci Res 1990;26:83-9.

44. Sadzot-Delvaux C, Debrus S, Nikkels A, Piette J, Rentier B. Varicella-zoster virus latency in the adult rat is a useful model for human latent infection. Neurology 1995;45:S18-20.

45. Fleetwood-Walker SM, Quinn JP, Wallace C, et al. Behavioural changes in the rat following infection with varicella-zoster virus. J Gen Virol 1999;80:2433-6.
46. Dalziel RG, Bingham S, Sutton D, et al. Allodynia in rats infected with varicella zoster virus - a small animal model for post-herpetic neuralgia. Brain Res Rev 2004;46:234-42.

47. Garry EM, Delaney A, Anderson HA, et al. Varicella zoster virus induces neuropathic changes in rat dorsal root ganglia and behavioral reflex sensitization that is attenuated by gabapentin or sodium channel blocking drugs. Pain 2005;118:97-111.

48. Hasnie FS, Breuer J, Parker S, et al. Further characterization of a rat model of varicella zoster virus-associated pain: Relationship between mechanical hypersensitivity and anxiety-related behavior, and the influence of analgesic drugs. Neuroscience 2007;144:1495-508.

49. Bennett GJ. Animals models of pain. In: Kruger L, ed. Methods in Pain Research. Boca Raton: CRC Press LLC, 2001:67-99.

50. Nurmikko T. Clinical features and pathophysiologic mechanisms of postherpetic neuralgia. Neurology 1995;45:54-5.

51. Dworkin RH. Post-herpetic neuralgia. Herpes 2006;13(Suppl 1):21A-7A.

52. Dworkin RH, Johnson RW, Breuer J, et al. Recommendations for the management of herpes zoster. Clin Infect Dis 2007;44(Suppl 1):S1-26.

53. Breuer J, Whitley R. Varicella zoster virus: Natural history and current therapies of varicella and herpes zoster. Herpes 2007;14(Suppl 2):25A-9A.

54. Brisson M, Gaya NJ, Edmunds WJ, Andrewsa NJ. Exposure to varicella boosts immunity to herpes-zoster: Implications for mass vaccination against chickenpox. Vaccine 2002;20:2500-7.

55. Edmunds WJ, Brisson M. The effect of vaccination on the epidemiology of varicella zoster virus. J Infect 2002;44:211-9.

56. Sugimoto T, Bennett GJ, Kajander KC. Transsynaptic degeneration in the superficial dorsal horn after sciatic nerve injury: Effects of a chronic constriction injury, transection, and strychnine. Pain 1990;42:205-13.

57. Scholz J, Broom DC, Youn DH, et al. Blocking caspase activity prevents transsynaptic neuronal apoptosis and the loss of inhibition in lamina II of the dorsal horn after peripheral nerve injury. J Neurosci 2005;25:7317-23.

58. Kennedy PG. Key issues in varicella-zoster virus latency. J Neurovirol 2002;8(Suppl 2):80-4.

59. Kennedy WR. Opportunities afforded by the study of unmyelinated nerves in skin and other organs. Muscle Nerve 2004;29:756-67. 


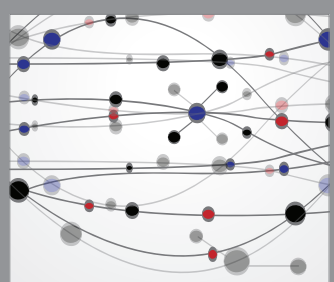

The Scientific World Journal
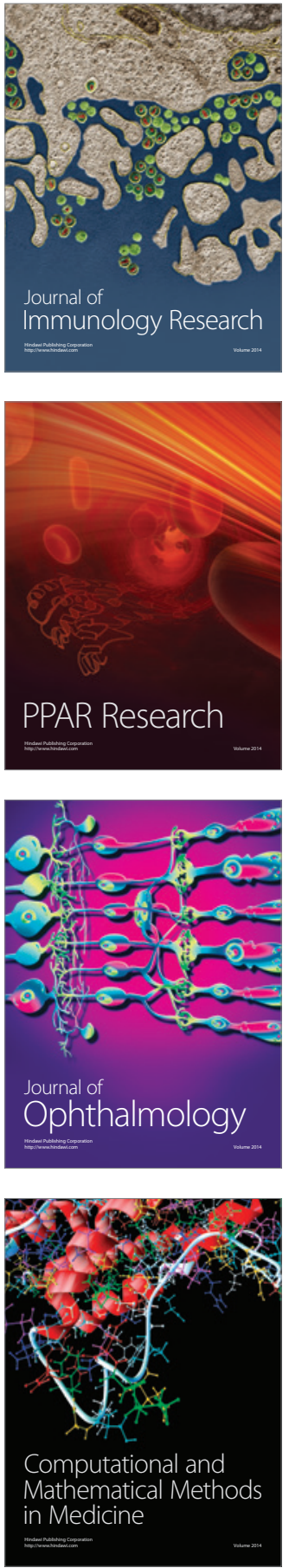

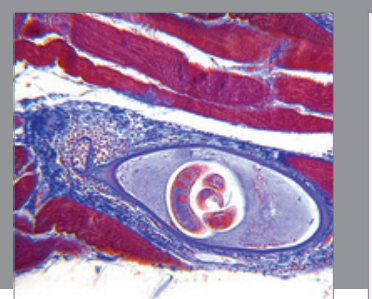

Gastroenterology Research and Practice

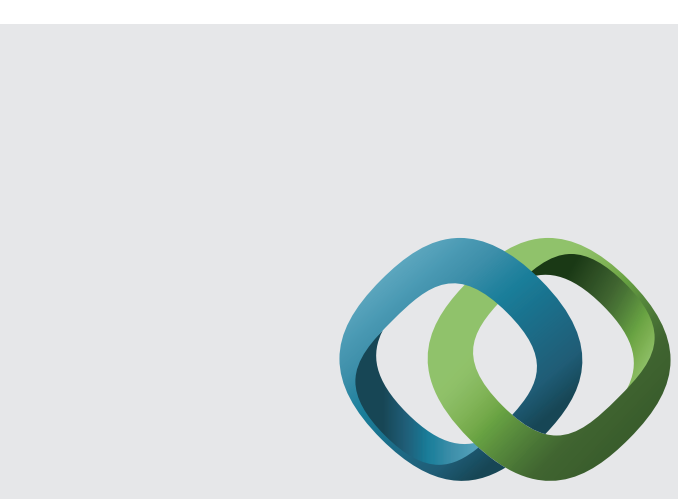

\section{Hindawi}

Submit your manuscripts at

http://www.hindawi.com
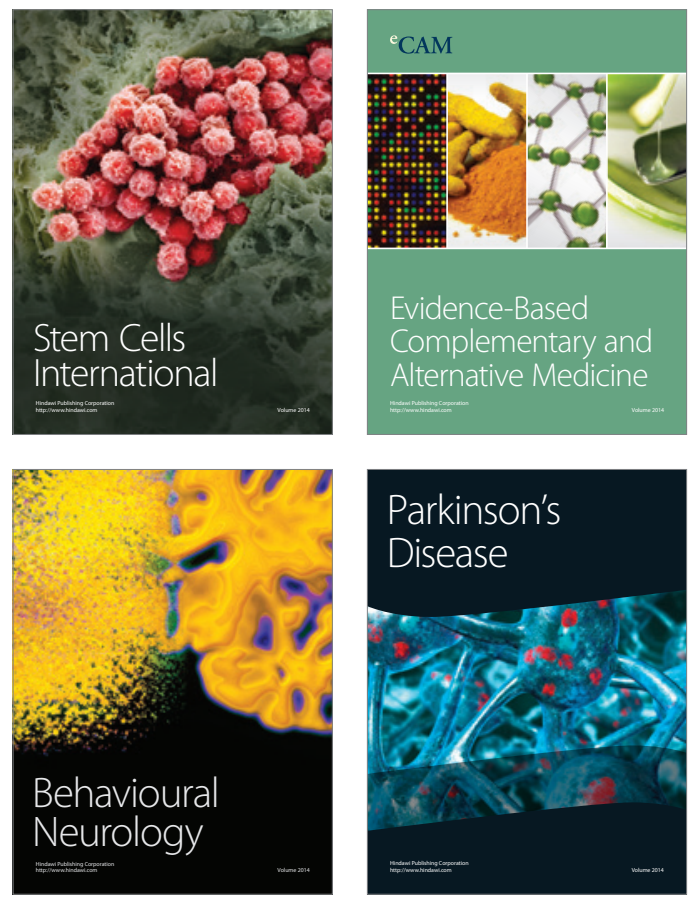
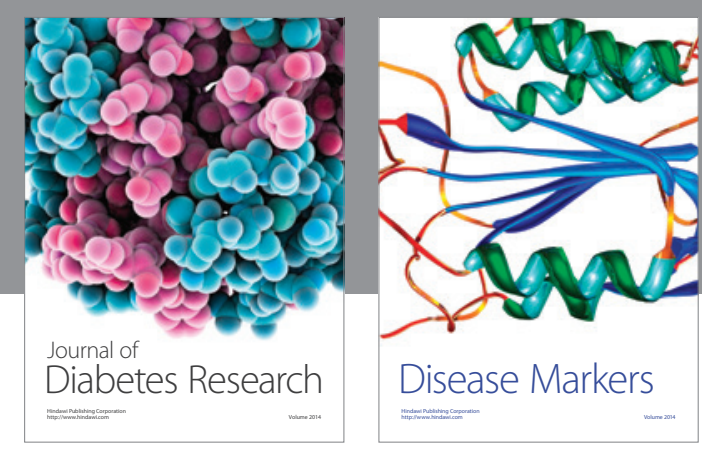

Disease Markers
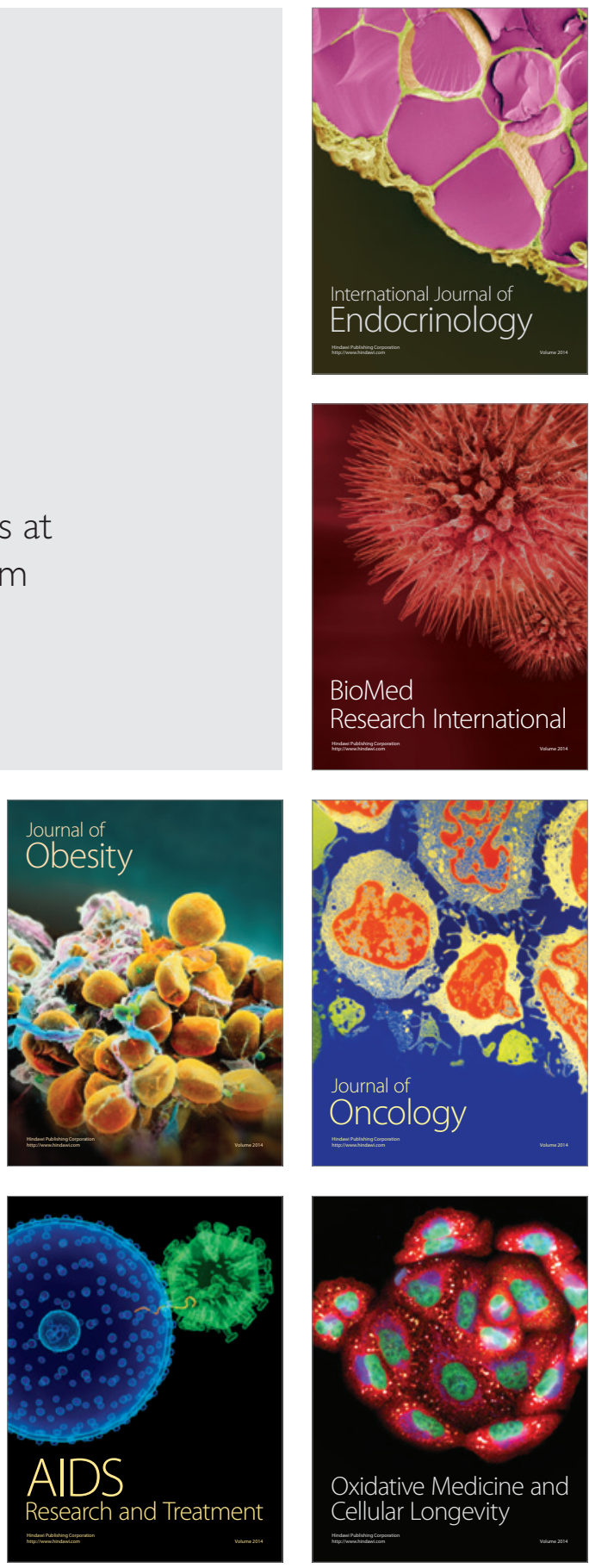